\title{
As primeiras expedições zoológicas no Brasil
}

\author{
Paulo E. Vanzolini
}

\section{O SYSTEMA NATURAE}

$\mathrm{O}$ ano de 1758 é um marco fundamental na história da zoologia; nele foi publicada a décima edição do Systema Naturae, de Lineu, a obra em que pela primeira vez foi adotado um sistema coerente de nomenclatura zoológica. Foi posteriormente convencionado, em um congresso internacional de zoologia, que a data de publicação fosse fixada arbitrariamente em 10 de janeiro de 1758, e que os nomes contidos nessa edição do Systema tivessem precedência sobre todos os outros, sendo excluídos os nomes anteriores a 1758 e escalonados cronologicamente, para fins de prioridade, todos os propostos a partir de então.

Nomenclatura é uma parte essencial de qualquer sistema taxonômico; sua codificação, especialmente com vistas ao reconhecimento de prioridades e à manutenção da estabilidade, demanda um certo aparato legalista. Este, infelizmente, permite e mesmo encoraja um certo espírito de rabulice em seus praticantes, o que resulta em certo desprestígio para a nomenclatura como especialidade. Nestes tempos em que as ciências naturais e as humanidades (ou, mesmo, a cultura geral) andam um tanto distanciadas, o desprestígio da nomenclatura entre os naturalistas tem tendido a ofuscar o brilho do Syste$m a$, sendo freqüentes as referências a Lineu, na literatura zoológica corrente, como se fosse um mero catalogador sem visão maior da ciência. Nada mais tolo.

O Systema é isso mesmo: uma síntese dos três reinos da natureza, organizados de acordo com um sistema classificatório coerente, alistando todas as espécies conhecidas, cada uma delas acompanhada de uma diagnose breve e de referências bibliográficas.

$O$ fato de as diagnoses serem breves é um dos pontos criticados por autores modernos que não conhecem as obras "pré-lineanas" (isto é, anteriores ao Systema) de Lineu. Estas, na área zoológica, são de dois tipos principais: teses orientadas por Lineu, em um livro chamado Amoenitates Academicae, e monografias sobre as coleções de história natural dos soberanos suecos, Museum Regis Adolphi Friderici I, Museum Principis, Museum Ludovicae Ulricae Reginae. Nessas obras são dadas descrições, de valor variável, é certo, mas freqüentemente de muito boa qualidade: as espécies são reconhecíveis. Com o apoio da literatura citada, o Systema era uma obra de consulta e referência do mais alto nível, merecedora de admiração mesmo que não tivesse codificado a nomenclatura binominal. Seu enorme impącto (obviamente anterior à $10^{a}$ edição) não se deveu, então, ao formalismo nomenclatural, mas ao fato de apresentar em conjunto, de forma organizada e documentada, toda a fauna conhecida, incluído o homem (cuja diagnose específica é nosce te ipsum), com suas raças geográficas, e os animais domésticos.

O Systema foi amplamente traduzido, parafraseado, e mesmo pirateado: a 11 ${ }^{\mathrm{a}}$ edição é clandestina. (Curiosamente, ê uma fraude sem grande valor comercial.) Transformouse em um ponto de partida ideal para obras de caráter monográfico, sobre determinados
PAULOE. VANZOLINI é diretor do Museu de Zoologia da USP e autor de, entre outros, An Annotated bibliography of the land of the tresh-water reptiles of South America (São Paulo, Museu de Zoologia da USP) e Répteis das caatingas, com A. M. M. Ramos-Costa e L. J. Vitt (Rio de Janeiro, Academia Brasileira de Ciências). 
grupos zoológicos, ou faunístico, de âmbito regional.

A segunda metade do século XVIII foi de grande fermentação zoológica, nas águas do Systema - que, obviamente, passou a ser erodido pelos progressos que facultou.

\section{AS GRANDES EXPLORAÇÕES}

Uma das características da zoologia do setecentos é a falta de critério geográfico. Por um lado, como um resto de tradição escolástica, praticava-se muito a discussão de animais conhecidos é somente da literatura que, é claro, raramente tinha caráter profissional, incluindo todos os autores clássicos que pudessem interessar ao zoólogo. Os animais da Biblia, por exemplo, foram objeto de uma Physica Sacra, de 1721. Por outro lado, o estado incipiente da metodologia sistemática ainda não permitia, em muitos casos, discernir as diferenças entre animais superficialmente semelhantes. Contudo, a acelerada exploração do mundo pelos países da Europa Ocidental, em busca de domínio e de comércio, acarretou uma equivalente aceleração da pesquisa zoológica.

O fim do século XVIII viu o início das grandes viagens de exploração marítima, freqüentemente de circunavegação. Era encargo explícito, embora não primordial, dos expedicionários a coleta de informações sobre os "produtos naturais" das regiōes visitadas. Essa tarefa, compreendendo coleta de exemplares e documentação iconográfica, ficava de início a cargo dos cirurgiões de bordo; progressivamente foram participando naturalistas, profissionais ou vocacionais (como Darwin).

Os resultados de muitas dessas viagens foram publicados. Eram obras maciças, luxuosas, maravilhosamente ilustradas e transbordando de fatos estranhos e fascinantes. $\mathrm{O}$ apetite da profissão zoológica aguçou-se para a exploração de terras novas, polares ou tropicais - exploração sistematizada e profissional.

\section{O Brasil Colônia}

Entre as obras repetidamente citadas por Lineu no Systema Nature está Margr. bras.. O título completo da obra é "História Naturalis Brasiliae, auspicio et beneficio Ilustriss. I. Mauritii Com. Nassao, illimus Provinciae et maris summi praefecti adornata in qua non tantum Plantae et Animalia, sed et Indigenarum morbi, ingenia et mores describuntur et iconibus supra quingentas illustrantur", de autoria de Georg Marcgrav, de Liebstad, juntamente com W. Pies (Piso) um dos naturalistas a serviço da corte holandesa em Pernambuco. Foi publicada em 1648, por Jean de Laet, nas casas de Elzevir em Amsterdam e Hack em Leiden (Lugdunium Batavorum). O Museu Paulista, por ocasião do cinqüentenário da Imprensa Oficial do Estado, publicou uma tradução, com reprodução das gravuras.

Há de se ter notado no título a menção a iconibus supra quingentas. Como bem era de esperar de uma obra executada na corte de Mauricio de Nassau, as ilustrações eram primorosas, como documento e como arte. Não foram usadas na publicação da obra; serviram para a confecção de xilogravuras de má qualidade. Os originais foram por muitos anos conservados em Berlim, e foram objeto de publicação. Em decorrência da Segunda Guerra Mundial extraviaram-se, entre outros tesouros artísticos evacuados na agonia da derrota. Foram recentemente rastreados na Polônia, e há esperança de recuperação.

No último quartel do século XVIII realizou-se a primeira (por muito tempo a única) expedição portuguesa ao Brasil. Alexandre Rodrigues Ferreira, baiano educado em Portugal, realizou, por ordem da Coroa, uma longa expedição (1783 a 1792) pelos vales do Amazonas e do alto Paraguai. A intenção da viagem, como se depreende das respectivas instruções, detalhadas e de aparência surpreendentemente moderna, bem como dos relatórios apresentados por Alexandre, era primordialmente geopolítica; constavam, contudo, as costumeiras recomendações sobre produtos naturais. A expedição, que contava com dois bons artistas, reuniu uma apreciável coleção zoológica, e excelente documentação iconográfica. O material foi, naturalmente, levado para Lisboa, e terminou, quando da invasão de Junot, apresado pelos franceses, mestres, ao tempo, nesse tipo de coleta de segunda ordem. Alexandre chegou a publicar sobre mamíferos que coletara, mas não tinha estatura de zoólogo. Quem realmente aproveitou sua coleta foram os naturalistas de Paris, que descreveram as espécies novas. A operação foi de nível moral muito baixo, mas os resultados científicos muito bons. 


\section{O REINO DO BRASIL}

Que a intenção de Portugal explorando a terra do Brasil era geopolítica e não científica torna-se muito claro quando se verifica o ciúme com que era a colônia fechada a viajantes estrangeiros. Faz parte do folclore científico brasileiro o caso acontecido com o famosíssimo Humboldt, em excursão pelo norte da América do Sul e proibido de entrar no Brasil por ser portador de perigosas idéias da Revolução Francesa. Porém, o mesmo Junot que adquiriu para o Museu de Paris as coleções de Lisboa contribuiu para abrir as portas do país à ciência. Tendo-se mudado a corte portuguesa para o Rio de Janeiro, instalou-se uma conjuntura inteiramente nova.

Em primeiro lugar, veio para o Rio o corpo diplomático, que não só podia trabalhar diretamente, e com novos instrumentos de pressão, em favor de seus compatriotas cientistas, como incluía muitos aficionados de história natural, que desenvolviam atividade pessoal de coleta e facilitavam a de viajantes. O mais conhecido é o mal-afortunado Barão Langsdorff, nobre alemão que havia servido no exército português (portanto falava a língua), que havia passado pelo Brasil na expedição marítima de Krusenstern, e era em 1813 o cônsul do imperador da Rússia no Rio.

O sítio de Langsdorff, "Mandioca", na Serra da Estrela (ainda existe) era ponto de parada, hospedagem e coleta de quanto intelectual europeu passasse pelo Rio. Um desses hóspedes, Augustin de Saint-Hilaire, levou Langsdorff em uma viagem a Minas Gerais. Langsdorff ainda voltou à Europa mas continuava interessado no Brasil e conseguiu ser comissionado pelo czar para comandar uma expedição aos sertões do país.

Essa expedição foi um desastre completo. Langsdorff era um amador e, aparentemente, um excêntrico. Contratou um zoólogo de primeira, Edouard Ménétriès, mas logo se desentendeu com ele; o substituto, Christian Hasse, também foi logo despedido. $O$ botânico Ludwig Riedel, um bom profissional, foi o ponto forte científico da expedição. Os artistas Hercule Florence e Aimé Adrien Taunay eram também excepcionais, e a iconografia que deixaram é o único resuitado palpáveí da viagem. Os materiais de história natural nunca foram publicados como um corpo; aparentemente a rotulagem do que sobreviveu é insatisfatória. Dolorosamente, Aimé Taunay afogou-se no Rio Guaporé. Langsdorff acabou de enlouquecer, foi levado para a Europa em regime de emergência e morreu sem ter se recuperado. Como dito, resultou dessa expedição uma linda iconografia paisagística e antropológica; de zoologia, praticamente nada.

Em 1814 começou sua exploração do Brasil um dos mais importantes cientistas da época, Maximilian, Prinz zu Wied Neuwied (Prince Max para os colegas). Este nobre e militar germânico, amigo de Langsdorff, realizou uma expedição pela Mata Atlântica, acompanhando a costa do Rio ao sul da Bahia e cortando para oeste para sair nas caatingas. Era um excelente naturalista, que coligiu notas de campo e publicou de forma exemplar não só a descrição, como os resultados científicos de sua viagem. Sua coleção, conservada no castelo da família, foi vendida ao American Museum of Natural

Na página ao lado, ao fundo, ilustraçбes de Rugendas da Spilotes pullatus, a caninana, e Liophis poecilogyrus, a falsa-coral, abaixo; no detalhe de cima, Hercule Florence, autor da ilustração do cágado (Phrynops geoffroanus); ao lado, 0 Ageneiosus brevifilis, peixe-palmito, do mesmo

Florence
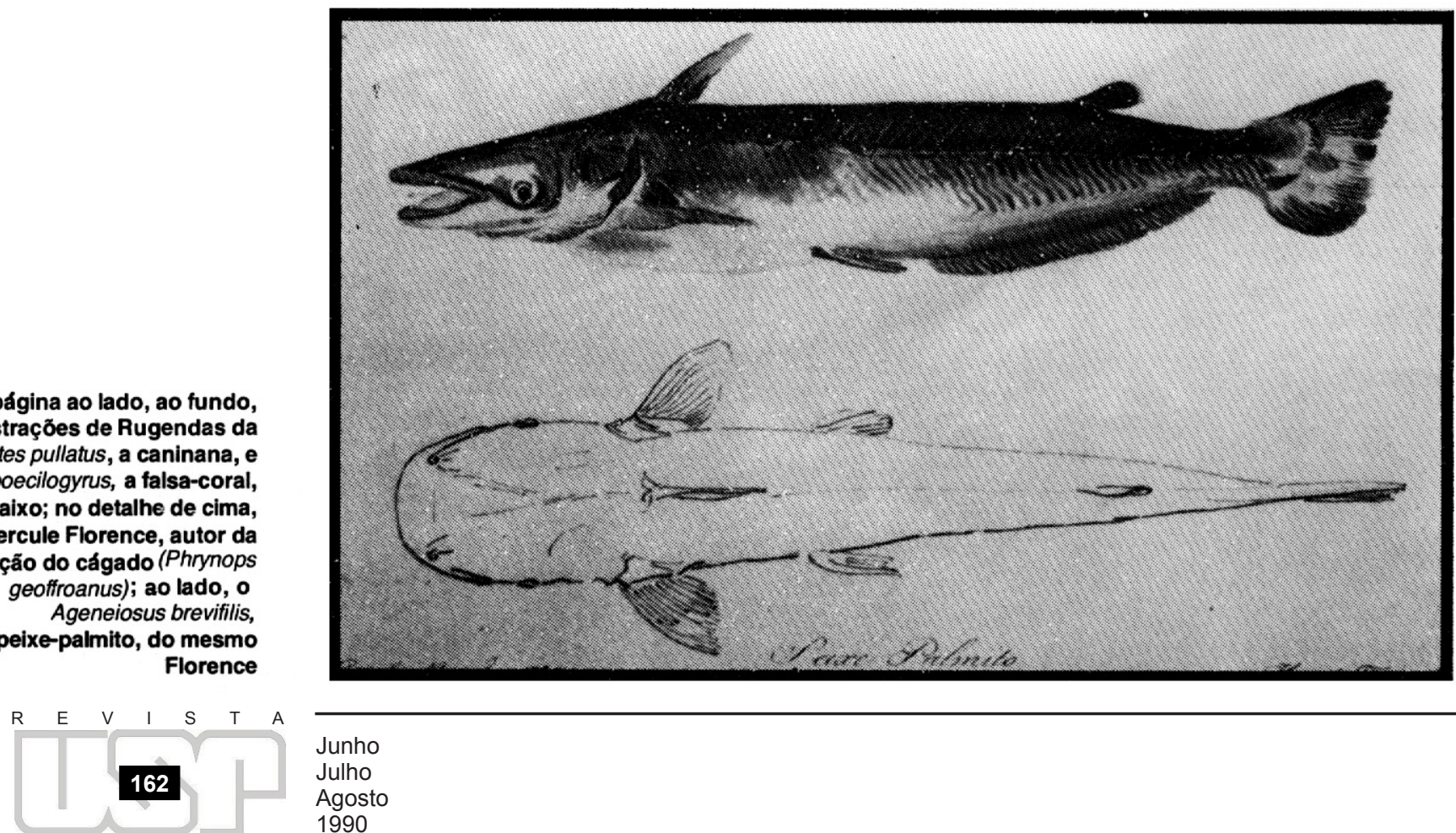

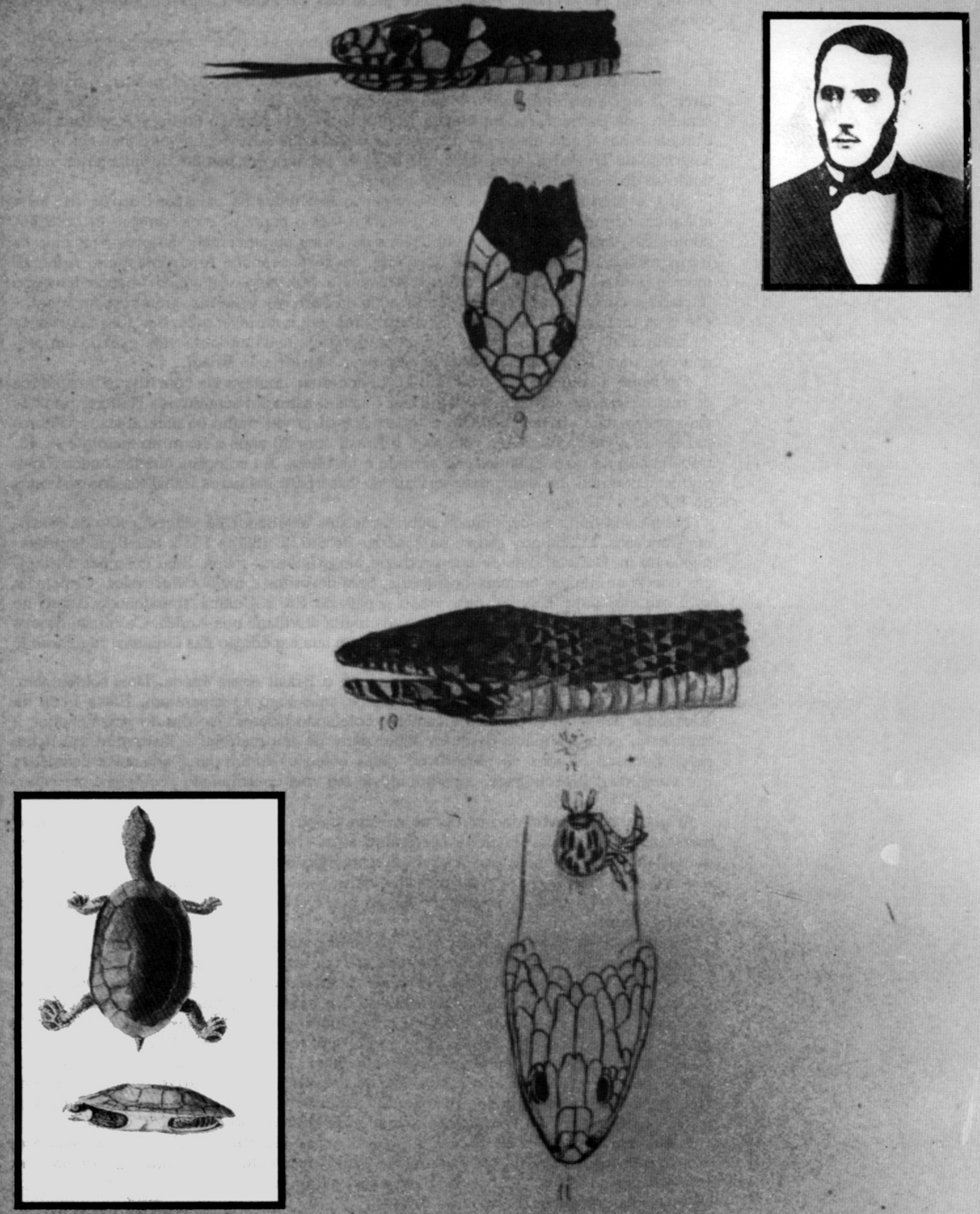

and

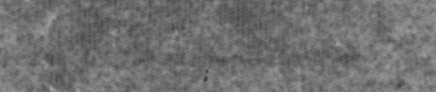


History, em Nova York, onde grande parte dos exemplares está disponível em boas condiçōes.

A seguinte expedição de grande porte, a de Spix e Martius, teve uma gênese complicada. D. Pedro I, ainda príncipe herdeiro, contraiu matrimônio com a arquiduquesa Leopoldina da Áustria. No séquito da mesma veio uma comissão científica. Adiante falaremos dos austro-húngaros. Mais importantes que eles, porém, foram os dois representantes da Baviera, Johann Baptist von Spix e Karl Friedrich Philip von Martius. Não está claro nas fontes históricas disponíveis o que tinha a Baviera a ver com o casamento austríaco de D. Pedro, mas, dado que o rei da Baviera era parente do imperador, e tratando-se do Brasil, a conexão parece natural.

Spix e Martius, de 1817 a 1820, viram quase todas as paisagens do Brasil: mata atlântica, cerrado, caatinga e hiléia. Faltaram-lhes o pantanal e os pampas. As coleções zoológicas, muito boas, foram publicadas de forma monumental; são provavelmente os livros mais caros sobre zoologia brasileira. Spix, que saiu da Amazônia muito enfermo, morreu pouco após chegar de volta à Alemanha. Martius viveu até os 74 anos, havendo iniciado e conduzido em parte a publicação da Flora brasiliensis, grandiosa na concepção e na realização. Martius era uma alma inquieta e curiosa; além das suas ocupações de naturalista, trabalhou muito na área etnográfica; mais tarde na vida ganhou um prêmio com uma monografia sobre como escrever a história do Brasil.

Passando à comissão austríaca de D. Leopoldina, contava ela com diversos membros de relativo mérito - Raddi, Mikan, Pohl - mas o astro foi sem dúvida Natterer, um dos mais teimosos e eficientes coletores que o Brasil já viu. Filho de naturalista, profissional desde o berço, Natterer veio para o Brasil com 30 anos e ficou no mato até os 48 , trabalhando na mata atlântica, no cerrado e na hiléia. As coleções que fez nunca foram publicadas como um todo, mas serviam de base para inúmeros trabalhos dos zoólogos de Viena.

$\mathrm{Na}$ mesma linha de caprichada publicação dos resultados de viagem estão os coletores franceses. D’Orbigny esteve na América do Sul de 1826 a 1833, trabalhando principalmente na Bolívia, país de que produziu um primoroso mapa. Suas coleções zoológicas encerram muitos animais brasileiros, bem descritos e melhor ilustrados. Castelnau, com seu assistente Deville, atravessou o país do Rio a Cuiabá, trabalhando depois no Pantanal e passando para a Bolívia. Após muita atividade nos Andes, Castelnau desceu o Amazonas - do Marañon a Belém. Terminou sua expedição nas Guianas, regressando a Paris ao fim de sete anos.

Poucos colecionadores ingleses exploraram o Brasil nessa época. Dois sobressaem: Wallace e Bates. Os dois começaram juntos, mas logo se separaram. Bates ficou na Amazônia por onze anos, metodicamente coletando insetos. Ao fim do prazo, voltou à Inglaterra, onde publicou pesquisa sobre parte de seu material - ilustrando seu nome pelos famosos estudos de mimetismo. Suas coleções foram parceladamente estudadas por numerosos especialistas, constituindo-se em uma contribuição decididamente valiosa.

Wallace, um homem do mato e, ao mesmo tempo, de teorias e idéias, viajou extensamente pela Amazônia brasileira por quatro anos (1848 a 1852). Perdeu suas coleções em um incêndio a bordo, mas deixou um maravilhoso livro $A$ narrative of travels on the Amazon and Rio Negro. Prosseguiu sua carreira de campo no Oriente e terminou por imortalizar-se ao propor, ao mesmo tempo que Darwin, o conceito de especiação por seleção natural.

Termino estas notas com Peter Wilhelm Lund e sua gente.

Lund, um dinamarquês de família rica, era um irremediável hipocondríaco, que passou 55 anos preparando-se para morrer de tuberculose a qualquer instante. Durante os 47 anos que passou em Lagoa Santa, Lund desenvolveu pertinaz atividade de coleta e descrição de material - não só fóssil, como muito divulgado, mas também recente. É grande o número de espécies de vertebrados cuja localidade-tipo é Lagoa Santa. Além disso, Lund trouxe bons coletores, especialmente J. T. Reinhardt, e entregou seus materiais a bons especialistas. Resultaram de seus esforços monografias zoológicas essenciais para o conhecimento dos vertebrados do Brasil Central - para não se falar na proteção e ajuda que deu a Warming, o fundador da botânica do cerrado.

Lund representa, e o fato é realçado pela enorme significação científica da sua obra, a transição do naturalista expedicionário para o residente, como figura maior no desvendamento da natureza tropical. Parece-me, assim, a figura adequada para periodizar essa fase da evolução científica do Brasil. 